\title{
EMISSION .SPECTRA OF TRIPLE ACTIVATED SrS PHOSPHORS
}

\author{
A.P. RAO \\ B.N. College of Engineering, Pusad (M.S.), 445215, India \\ O.P. SINHA \\ SSLJ Post Graduate College, Vidisha (M.P.), 464001, India \\ V.G. Machwe and A.S. Mehta \\ S.A. Technological Institute, Vidisha (M.P.), 464002, India \\ (Received December 12, 1994; revised version September 29, 1995; \\ in final form January 12, 1996) \\ Fluorescence spectra of strontium sulphide phosphors activated by three \\ activators viz. $\mathrm{Mn}, \mathrm{Cu}$, and $\mathrm{Gd}$ individually and in different combinations \\ have been discussed at length. X-ray is used as excitation source. Probable \\ inferences are drawn regarding energy transfer phenomenon. The two chan- \\ nels for transfer of energy are concluded in present phosphor series. A model \\ is also proposed.
}

PACS numbers: $33.50 .-\mathrm{j}$

\section{Introduction}

Luminescence properties of polycrystalline powder phosphors have been studied widely so far by many researchers. The roughness of powder phosphors plays major role in the properties of emitted light which is related to trapped impurity [1]. The alkaline earth sulphide phosphors have been found more efficient if double or triple activators are used [2]. SrS has been selected as the base material because it shows sensitivity with an ability for energy storage and quick response [3-5]. Hence fluorescence emission of $\mathrm{SrS}: \mathrm{Mn}, \mathrm{Cu}, \mathrm{Gd}$ phosphor is carried out to seek information about energy levels operative at $299 \mathrm{~K}$. 


\section{Experiment}

The purification of basic ingredients and preparation are reported in our earlier publications $[6,7]$. In short, analytical reagent grade strontium sulphate mixed with appropriate amount of carbon (reducing agent), sodium thiosulphate (flux) and activators ( $\mathrm{Gd}, \mathrm{Mn}$ and $\mathrm{Cu}$ in different concentrations) is fired at $1200 \pm 10 \mathrm{~K}$. Using Bhawalkar's method, three series of phosphors are thus prepared (Table I). These phosphors are excited by X-rays (Philips X-ray machine type 11704) operated at $30 \mathrm{kV}, 10 \mathrm{~mA}$, using $\mathrm{Cu}$ target, and emission is recorded on Bellingham and Stantley spectrometer coupled with IP-21 photomultiplier tube. In each series, all the three activators are present, out of which two are kept constant and the third one is varied successively.

TABLE I

Sample details and fluorescence emission spectra at temperature $299 \mathrm{~K}$.

\begin{tabular}{|c|c|c|c|c|c|c|}
\hline \multirow{2}{*}{$\begin{array}{c}\text { Serial } \\
\text { No. }\end{array}$} & \multirow{2}{*}{$\begin{array}{c}\text { Sample } \\
\text { Nos. }\end{array}$} & \multicolumn{3}{|c|}{ Concentration of activators } & \multirow{2}{*}{$\begin{array}{c}\text { Peak } \\
\text { wavelength } \\
\text { in } \mathbf{n m} \\
\end{array}$} & \multirow{2}{*}{$\begin{array}{c}\text { Peak } \\
\text { intensity } \\
\text { in arb. units }\end{array}$} \\
\hline & & Copper & Manganese & Gadolinium & & \\
\hline 1 & 24 & $1 \times 10^{-6}$ & $2 \times 10^{-2}$ & - & 550 & 84 \\
\hline 2 & 16 & - & $2 \times 10^{-2}$ & - & 575 & 225 \\
\hline 3 & 22 & $1 \times 10^{-6}$ & - & - & 532 & 45 \\
\hline 4 & 27 & - & - & $1 \times 10^{-4}$ & 532 & 78 \\
\hline $5^{*}$ & A1 & $1 \times 10^{-6}$ & $2 \times 10^{-2}$ & $1 \times 10^{-3}$ & 546 & 20 \\
\hline 6 & A2 & $1 \times 10^{-6}$ & $2 \times 10^{-2}$ & $5 \times 10^{-3}$ & 544 & 56 \\
\hline 7 & A4 & $1 \times 10^{-6}$ & $2 \times 10^{-2}$ & $5 \times 10^{-2}$ & 556 & 84 \\
\hline 8 & A5 & $1 \times 10^{-6}$ & $2 \times 10^{-2}$ & $7 \times 10^{-2}$ & 550 & 116 \\
\hline 9 & $\mathrm{~A}^{\prime}$ & $1 \times 10^{-6}$ & $2 \times 10^{-2}$ & $9 \times 10^{-2}$ & 555 & 85 \\
\hline 10 & A7 & $1 \times 10^{-6}$ & $2 \times 10^{-2}$ & $1.8 \times 10^{-1}$ & 551 & 72 \\
\hline 11 & $\mathrm{~B} 2$ & $1 \times 10^{-6}$ & $1 \times 10^{-3}$ & $9 \times 10^{-2}$ & 551 & 43 \\
\hline 12 & B3 & $1 \times 10^{-6}$ & $3 \times 10^{-3}$ & $9 \times 10^{-2}$ & 552 & 75 \\
\hline 13 & B4 & $1 \times 10^{-6}$ & $5 \times 10^{-3}$ & $9 \times 10^{-2}$ & 547 & 85 \\
\hline 14 & B5 & $1 \times 10^{-6}$ & $8 \times 10^{-3}$ & $9 \times 10^{-2}$ & 555 & 97 \\
\hline 15 & $\mathrm{~B}^{\prime}$ & $1 \times 10^{-6}$ & $2 \times 10^{-2}$ & $9 \times 10^{-2}$ & 555 & 85 \\
\hline 16 & B7 & $1 \times 10^{-6}$ & $2 \times 10^{-2}$ & $9 \times 10^{-2}$ & 554 & 47 \\
\hline 17 & $\mathrm{C}^{\prime}$ & $1 \times 10^{-6}$ & $2 \times 10^{-2}$ & $9 \times 10^{-2}$ & 555 & 85 \\
\hline 18 & $\mathrm{C} 3$ & $5 \times 10^{-5}$ & $2 \times 10^{-2}$ & $9 \times 10^{-2}$ & 556 & 47 \\
\hline 19 & $\mathrm{C} 4$ & $1 \times 10^{-4}$ & $2 \times 10^{-2}$ & $9 \times 10^{-2}$ & 556 & 45 \\
\hline 20 & $\mathrm{C} 7$ & $5 \times 10^{-3}$ & $2 \times 10^{-2}$ & $9 \times 10^{-2}$ & 563 & 25 \\
\hline 21 & $\mathrm{C} 8$ & $1 \times 10^{-2}$ & $2 \times 10^{-2}$ & $9 \times 10^{-2}$ & 556 & 19 \\
\hline
\end{tabular}

* Concentration of activator is per $10 \mathrm{~g}$ of base material. 


\section{Result and discussion}

The result of representative samples are shown in graph (Fig. 1) and the numerical values are tabulated in Table I. In series $A, \mathrm{Gd}$ alone varies while $\mathrm{Cu}$ and $\mathrm{Mn}$ are kept constant. The wavelength of emission peak lies between $544 \mathbf{n m}$ and $556 \mathrm{~nm}$ for various concentration of $\mathrm{Gd}$. However, change in peak intensity has been observed in series $A$. In series $B$, in which $\mathrm{Mn}$ alone varies while $\mathrm{Cu}$ and $\mathrm{Gd}$ are constant, the peak wavelength varies between $547 \mathrm{~nm}$ and $555 \mathrm{~nm}$. A small but slight shift towards higher wavelength side can be seen with rise of concentration of $\mathrm{Mn}$. While in series $C$, in which $\mathrm{Cu}$ alone varies, the peak wavelength of emission intensity is obtained between $547 \mathrm{~nm}$ and $563 \mathrm{~nm}$ with irregular variation of shift of peak wavelength with change in concentration of copper. In general, only one emission band is observed for all the three series $\bar{A}$, $B$ and $C$ (refer Table I). The concentration of activator seems to play interesting role in present series of phosphors. When the peak intensity of emission reduces with increase in concentration of activators (other than concentration quenching), it is attributed to the defect of matrix or host. This has not been observed in present case. The prepared phosphors do not show presence of $\mathrm{SrO}$ as tested by $\mathrm{X}$-ray diffraction method and hence do not contribute to luminescence [8]. Thus, it seems reasonable to associate the observed band to the impurity rather than defects. The pointwise discussions are given below.

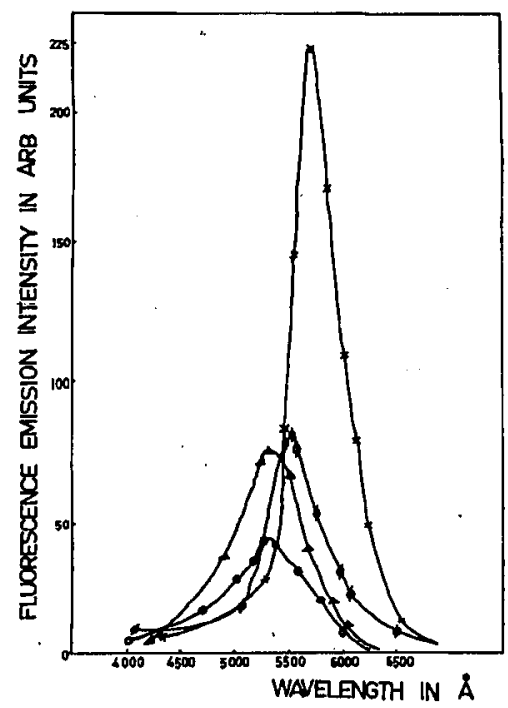

Fig. 1. Variation of fluorescence emission intensity with wavelength of $\mathrm{SrS}: \mathrm{Cu}, \mathrm{Mn}, \mathrm{Gd}$ phosphors at $299 \mathrm{~K}: \times-16, \phi-\mathrm{A} 4, \Delta-\mathrm{B} 3, \circ-\mathrm{C} 4$. 


\subsection{Gadolinium impurity}

The emission due to $\mathrm{Gd}$ is reported [9]. Aterkar et al. [10] reported four lines of Gd in CaS lattice doped simultaneously with Sm. Instead of lines, a band emission has been reported by Laud and Kulkarni [11] in SrS:Gd when doped simultaneously with $\mathrm{Cu}$ at $553 \mathrm{~nm}$. It is attributed to $\mathrm{Gd}$ by the same author. Pringsheim [12] reported that Gd alone is not fluorescent in SrS. In present case no emission line is observed. A band in the region of $548 \mathrm{~nm}$ is observed in series $A$, where $\mathrm{Gd}$ alone varies. This may be due to sensitization by other activators present. According to Laud and Kulkarni, the increase in concentration of $\mathrm{Cu}$ enhances peak intensity and shifts the band from $548 \mathrm{~nm}$ to $553 \mathrm{~nm}$. Kingsley [13] reported that no energy transfer is possible to $\mathrm{Gd}$ from $\mathrm{Cu}$ in $\mathrm{ZnS}: \mathrm{Cu}, \mathrm{Gd}$ phosphors because of the fact that lowest excited state of $\mathrm{Gd}^{3+}$ is greater than band gap of $\mathrm{ZnS}$. But this compatibility is not faced by $\mathrm{SrS}$ because of its wider band gap. Therefore, energy transfer is possible to $\mathrm{Gd}$ from copper in this case. The strong phosphorescence of the present phosphor also favours such transfer of energy. The luminescence of $\mathrm{Gd}^{3+}$ ion arises from transition due to excited ${ }^{6} P_{7 / 2}$ state to the ground ${ }^{8} S_{7 / 2}$ state. It becomes possible for $\mathrm{Gd}$ to be sensitized, if emission of some other activator overlaps the absorption edge of Gd. The energy transfer from $\mathrm{Gd}^{3+}$ ion to activator is subjected strongly on the nature, site and concentration of other activators incorporated in addition to $\mathrm{Gd}$. In the present case $\mathrm{Gd}^{3+}$ with $\mathrm{Na}^{+}$as a charge compensator may be substituting for two $\mathrm{Sr}^{2+}$ ions. This model of charge compensation gets supported by observing the shift of band-peak wavelength towards higher wavelength side with increase in concentration of $\mathrm{Gd}^{3+}$ ions (series $A$ ). In $\mathrm{CaF}: \mathrm{Gd}, \mathrm{Mn}$ intracentric energy transfer due to non-cubic centres of $\mathrm{Gd}^{3+}$ is reported [14] and concluded that $\mathrm{Gd}$ centres do not exhibit emission themselves. However, the observed variation of emission intensity in present series of phosphors can be attributed to Gd and can help in deriving conclusion that it acts as an activator. After increasing the concentration of Gd from $7 \times 10^{-2} \mathrm{~g}$ the decrease in intensity may be attributed to concentration quenching due to dense ion packing that in turn give rise to nonradiative transitions and favours sensitization of ions.

\subsection{Manganese impurity}

$\mathrm{Gd}^{3+}$ has preferential tendency to transfer energy to $\mathrm{Mn}^{2+}$, thus $\mathrm{Mn}$ gets normally sensitized by $\mathrm{Gd}^{3+}$ in these lattices $[15,16]$. The energy transfer from sensitizer to activator becomes predominant at lower concentrations. In the present case it may be inferred that Gd may be transferring its energy to $\mathrm{Mn}^{2+}$ and playing a role of mediator. The energy transfer from $\mathrm{Gd}$ to $\mathrm{Mn}^{2+}$ may possibly be taking place by resonance transfer. The ionic radii and ionic charges favour $\mathrm{Gd}^{3+}$ to be substitutional. The energy levels of $\mathrm{Mn}^{2+}$ are ${ }^{6} S,{ }^{4} G,{ }^{4} P,{ }^{4} D$ and ${ }^{4} F$ where ${ }^{6} S$ is a ground state. $\mathrm{Mn}^{2+}$ after reaching higher excited state transfers energy nonradiatively to the adjacent lower excited state until it reaches back lowest ${ }^{4} G$ excited state. It can be assumed that emission is due to transition within $\mathrm{Mn}^{2+}$ ions as the gap between lowest excited state and ground state prefers radiative transfer of energy. Manganese gives fluorescence band in yellow-orange region and it is reported to be due to $\mathrm{Mn}^{2+}$ state having $d^{5}$ configuration [17]. $\mathrm{Mn}^{2+}$ is 
known to be a classical acceptor in energy transfer because of $3 d \rightleftharpoons 3 d$ forbidden transition in visible and near UV region. In series $B$ (concentration of $\mathrm{Mn}$ varies only) it has been observed that with increase in concentration of $\mathrm{Mn}$, increase in intensity of the band takes place up to sample B5 beyond which decrease in intensity is observed. This can be attributed to concentration quenching.

A band in SrS phosphor is observed at $575 \mathrm{~nm}$ when doped only with Mn (sample No. 16). Band at $580 \mathrm{~nm}$ has been reported by Sivraman [18] in SrS:Mn,Zr phosphors and Bhushan [19] has reported a band at $560 \mathrm{~nm}$ in SrS:Mn phosphors. Resonance transfer of energy to $\mathrm{Mn}$ from other incorporated activators has been concluded by Bhushan [20]. Our results of series $B$ are in accordance with these interpretations.

\subsection{Copper impurity}

For series $C$, sample $\mathrm{C}^{\prime}$ exhibits maximum intensity which further decreases with increase in concentration of copper. This fact supports the idea of concentration quenching. Sample C7 indicates peak wavelength at $563 \mathrm{~nm}$. However, peak wa velength of sample $\mathrm{SrS}: \mathrm{Cu}, \mathrm{Mn}$ (sample No. 24) shifts to lower wavelength side, which favours sensitization of $\mathrm{Mn}^{2+}$ bu $\mathrm{Cu}^{2+}$. The decrease in intensity may be assigned to destructive dipole-dipole interaction on account of closeness of dopant ions and probably energy transfer may be taking place by magnetic dipole-dipole interaction rather than forbidden [21] electronic dipole-dipole interactions.

Emission from $\mathrm{Mn}^{2+}$ seems to dominate in all the three series viz. $A, B$ and $C$. The ionic radii of $\mathrm{Cu}(0.96 \AA)$ and $\mathrm{Mn}(0.80 \AA)$ favour substitutional and interstitial site, along with $\mathrm{Gd}$ at substitutional site.

\section{Conclusion}

It seems probable that energy from $\mathrm{Cu}^{2+}$ may be transferred directly to $\mathrm{Mn}^{2+}$ and also via $\mathrm{Gd}^{3+}$. There may be two ways for transferring energy in present case. A cascade mechanism is expected to be involved between $\mathrm{Cu}$ and $\mathrm{Gd}$. And finally the energy may be transferred to $\mathrm{Mn}$ by resonance transfer. Band spectra of $\mathrm{Mn}^{2+}$ may be attributed to the electronic transition, involving the outermost electrons whose resultant principal angular momentum and spin quantum number change during transitions. Usually increase in temperature of phosphor results in higher probability of radiationless transition within the activator ions and results in temperature quenching. In the present case decrease in intensity of emission is observed without shift of the peak when fluorescence is recorded at temperature $363 \pm 2 \mathrm{~K}$ (Fig. 2 and Table II). This lowering of intensity can be attributed to interaction of thermally released and optically released carriers causing dissipation of energy to the lattice and hence lowering of peak intensity is observed.

A comparative study of phosphorescence peak of samples (Fig. 3) and its spectral shift (Table III) supports the importance of sensitization, charge compensation and concentration quenching.

Averaged out trap levels are formed almost at one depth irrespective of concentration of activators in all the series. This has been also confirmed by thermoluminescence and emission decay studies of the phosphors [22, 23]. 
TABLE II

Fluorescence emission spectra at temperature $363 \pm 2 \mathrm{~K}$.

\begin{tabular}{c|c|c|c}
\hline \hline $\begin{array}{c}\text { Serial } \\
\text { No. }\end{array}$ & $\begin{array}{c}\text { Sample } \\
\text { Nos. }\end{array}$ & $\begin{array}{c}\text { Peak wavelength } \\
\text { in nm }\end{array}$ & $\begin{array}{c}\text { Peak intensity } \\
\text { in arb. units }\end{array}$ \\
\hline 1 & $\mathrm{~A} 1$ & 546 & 16 \\
2 & $\mathrm{~A} 2$ & 544 & 40 \\
3 & $\mathrm{~A} 4$ & 556 & 68 \\
4 & $\mathrm{~A} 5$ & 550 & 90 \\
$5^{*}$ & $\mathrm{~A}^{\prime} / \mathrm{B}^{\prime} / \mathrm{C}^{\prime}$ & 555 & 70 \\
6 & $\mathrm{~A} 7$ & 551 & 50 \\
7 & $\mathrm{~B} 2$ & 551 & 30 \\
8 & $\mathrm{~B} 3$ & 552 & 57 \\
9 & $\mathrm{~B} 4$ & 547 & 62 \\
10 & $\mathrm{~B} 5$ & 555 & 71 \\
11 & $\mathrm{~B} 7$ & 554 & 25 \\
12 & $\mathrm{~B} 8$ & 555 & 22 \\
13 & $\mathrm{C} 3$ & 556 & 34 \\
14 & $\mathrm{C} 4$ & 556 & 30 \\
15 & $\mathrm{C} 8$ & 563 & 17 \\
16 & $\mathrm{C} 8$ & 556 & 10 \\
\hline
\end{tabular}

* Sample common to all three series.

TABLE III

Phosphorescence emission spectra at temperature $299 \mathrm{~K}$.

\begin{tabular}{c|c|c|c}
\hline \hline $\begin{array}{c}\text { Serial } \\
\text { No. }\end{array}$ & $\begin{array}{c}\text { Sample } \\
\text { Nos. }\end{array}$ & $\begin{array}{c}\text { Peak wavelength } \\
\text { in } \mathrm{nm}\end{array}$ & $\begin{array}{c}\text { Peak intensity } \\
\text { in arb. units }\end{array}$ \\
\hline 1 & $\mathrm{~A} 4$ & 570 & 31 \\
2 & $\mathrm{~A} 6$ & 560 & 60 \\
3 & $\mathrm{~B} 3$ & 565 & 29 \\
4 & $\mathrm{~B} 4$ & 565 & 34 \\
$5^{*}$ & $\mathrm{~A}^{\prime} / \mathrm{B}^{\prime} / \mathrm{C}^{\prime}$ & 547 & 35 \\
6 & $\mathrm{~B} 7$ & 560 & 50 \\
7 & $\mathrm{C} 3$ & 575 & 44 \\
8 & $\mathrm{C} 7$ & 570 & 31 \\
\hline
\end{tabular}

* Sample common to all three series. 

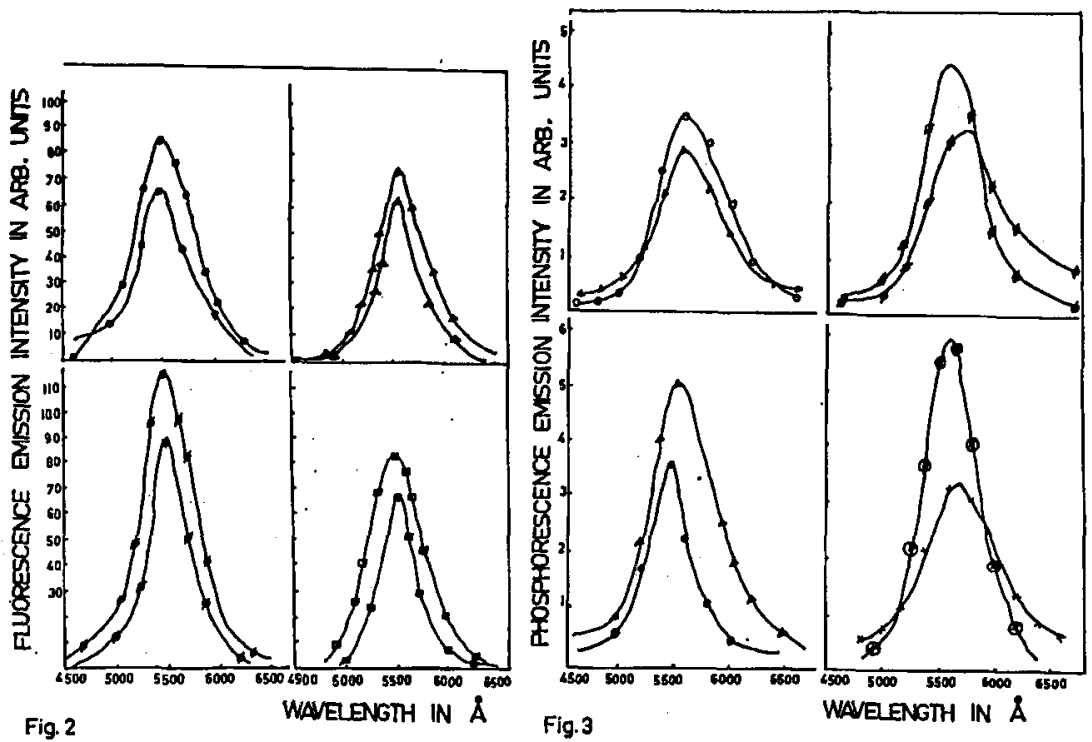

Fig. 2. Comparison of variation of fluorescence emission intensity with wavelength of $\mathrm{SrS}: \mathrm{Cu}, \mathrm{Mn}, \mathrm{Gd}$ phosphors at $299 \mathrm{~K}$ and $363 \pm 2 \mathrm{~K}: \circ-\mathrm{B} 4, \Delta-\mathrm{C} 2, \phi-\mathrm{A} 5, \square-$ A4 at temperature $299 \mathrm{~K}, \bullet-\mathrm{B} 4$, full $\Delta-\mathrm{C} 2$, full $\phi-\mathrm{A} 5$, $-\mathrm{A} 4$ at temperature $363 \pm 2 \mathrm{~K}$

Fig. 3. Variation of phosphorescence emission intensity with wavelength of $\mathrm{SrS}: \mathrm{Cu}$, Mn,Gd phosphors: $x-\mathrm{A4}, \bigotimes-\mathrm{A} 6, \Delta-\mathrm{B} 3, \circ-\mathrm{B} 4, \bullet-\mathrm{B}^{\prime}$, full $\Delta-\mathrm{B} 7, \phi-$ C3, full $\phi-\mathrm{C} 7$.

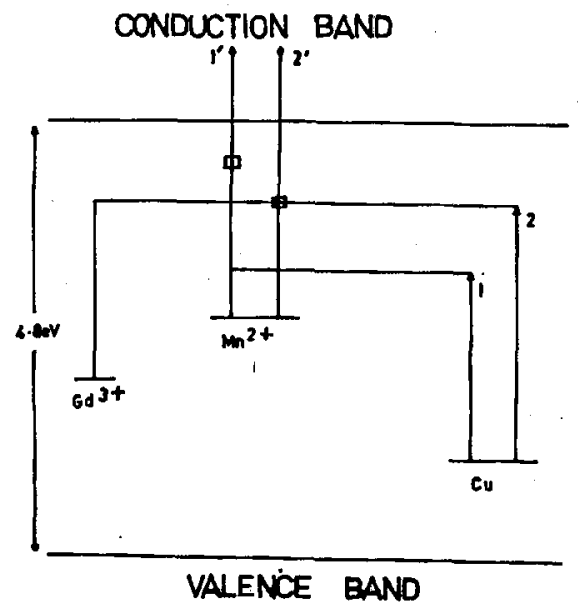

Fig. 4. Proposed model: $1-\mathrm{Cu}, \mathrm{Mn}$ resonance transfer, $2-\mathrm{Cu}$, Gd cascade, $\mathbf{1}^{\prime}$ and $2^{\prime}$ - outcoming radiation dominated by $\mathrm{Mn}^{2+}$. 
The proposed model (Fig. 4) explains the observed emission as an average result of competition between two channels of energy transfer.

\section{References}

[1] B. Dereaud, J.Y. Emery, A. Chomette, B. Lambert, M. Baudet, Appl. Phys. Lett. 45, 1078 (1984).

[2] S.P. Killer, J.E. Mapes, G. Cheroff, Phys. Rev. 108, 663 (1957).

[3] S.S. Paliwal, O.P. Sinha, Phys. Status Solidi A 38, 73 (1976).

[4] M.G. Patil, P.D. Lawenger, Pramana (India) 15, 91 (1980).

[5] J. Hernandez, S.A. Tarol, Opt. Pure Appl. (Spain) 17, 103 (1984).

[6] A.S. Mehta, V.G. Machwe, R.C. Saxena, Indian J. Phys. 49, 761 (1975).

[7] O.P. Sinha, S. Shivraman, Indian J. Pure Appl. Phys. 10, 131 (1972).

[8] A.P. Rao, Ph.D. Thesis, Bhopal Univ., Bhopal (M.P.), India 1988.

[9] N.P. Efrayashina, N.I. Smirdova, Jpn. Spec. 22, 438 (1975).

[10] S.G. Aterkar, O.P. Sinha, A.S. Mehta, in: Proc. National Conf. on Electrical and Optical Properties of Solids, Ed. R. Nath, Department of Physics at Dr. H.S. Gour V.V., Sagar, India 1987, p. 298.

[11] B.B. Laud, V.W. Kulkarni, Indian Pure Appl. Phys. 19, 47 (1981).

[12] P. Pringsheim, Fluorescence and Phosphorescence, Wiley, New York 1949.

[13] J.D. Kingsley, Phys. Rev. Lett. 14, 136 (1945).

[14] D.L. Dexter, J.H. Schulman, J. Chem. Phys. 22, 1063 (1954).

[15] J.Th.W. de Hair, J. Lumin. 2, 19 (1979).

[16] J.Th.W. de Hair, W.L. Konijnendijk, J. Electrochem. Soc. 127, 161 (1980).

[17] N. Rokday, Ph.D. Thesis, Giwaji Univ., Gwalior, India 1974.

[18] S. Sivraman, Indian J. Pure Appl. Phys. 14, 1015 (1976).

[19] S. Bhushan, Indian J. Pure Appl. Phys. 13, 872 (1975).

[20] S. Bhushan, Indian J. Pure Appl. Phys. 15, 486 (1978).

[21] M.D. Lamb, Lum. Spect. Acad. Press (Lond.) 23, 100 (1978).

[22] A.P. Rao, O.P. Sinha, V.G. Machwe, A.S. Mehta, Acta Ciencia Indica XVII, M,1,119 (1991).

[23] A.P. Rao, O.P. Sinha, V.G. Machwe, A.S. Mehta, accepted for publication in J. Pure Appl. Phys., School of Optics, Hyderabad, India. 